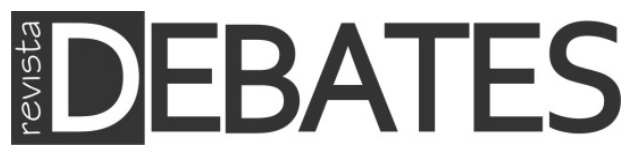

\title{
O avanço eleitoral da extrema direita no século XXI e seus efeitos nos sistemas de partidos europeus
}

\author{
The electoral advancement of the far right in the 21st century and its \\ effects on European party systems
}

\section{Manuel Sánchez de Dios}

\section{Resumo}

A partir da análise do formato dos sistemas de partidos, este artigo estuda a evoluçáo do apoio eleitoral dos partidos de extrema direita da Europa ocidental e seus efeitos sobre a fragmentaçáo de cada sistema, assim como as consequências que a volatilidade eleitoral tem sobre o realinhamento dos eleitores. Também se considera a polarizaçáo dos partidos analisando as issues mais relevantes em seus programas de acordo com os dados do Manifesto Project. Conclui-se que não há uma pauta homogênea no desenvolvimento dos partidos de extrema direita europeus no século XXI, embora haja um aumento do pluralismo em geral e a competição no eixo esquerda/direita; que na maior parte dos casos houve um realinhamento do eleitorado de tipo secular; que em alguns casos há uma elevada fragmentaçáo e polarização que não chega a ser relevante para a governabilidade dos países, e, por último, há uma tendência geral de confluência estratégica desses partidos na moderaçáo programática para ampliar a base eleitoral.

\section{Palavras-chave}

Partido Políticos; Extrema Direita; Multipartidarismo; Polarização; Realinhamento Eleitoral.

\section{Abstract}

Based on the analysis of the of party system format, this article studies the evolution of electoral support for far-right parties in Western Europe and its effects on the fragmentation of each system, as well as the consequences that electoral volatility provokes on voter realignment. By analyzing the most relevant issues in their programs according to data from the Manifesto Project, we evaluate the polarization of the parties. It is concluded that there is no homogeneous pattern in the development of the European radical right parties in the 21st century, though pluralism and competition on the left/right axis have increased in general. In most cases, there has been a secular-type realignment of the electorate. In some cases, there is a high degree of fragmentation and polarization without this being relevant for the governability of the countries. Finally, there is a general trend of strategic confluence of these parties in programmatic moderation to broaden the electoral base.

\section{Keywords}

Political Parties; Radical Right; Multiparty Systems; Polarization; Voter Realignment. 


\section{Introdução}

A transformação dos sistemas de partidos europeus é um fenômeno estudado desde a década de 1960 (WEBB, 2002b). Nos anos 1970, surgiram os partidos ecologistas e a "nova esquerda", e atualmente é significativa a aparição de novos partidos de direita radical, como o Partido da Independência do Reino Unido (UKIP), Alternativa pela Alemanha e Vox na Espanha.

Tomando como referência o apoio eleitoral médio que alcançam os partidos com representação parlamentar, comprovamos que no século XXI os partidos de extrema direita cresceram com força na Europa Ocidental, pois passaram de 3,6\% dos votos nas eleiçóes da década de 1980 para $14 \%$ dos votos nas eleiçóes mais recentes. Além disso, os partidos incrementaram sua implantação, pois conseguem representação parlamentar em quatorze países da Europa ocidental depois de 2015, enquanto nos anos 1980 somente tinham representação relevante em cinco países (Quadro 1).

É por isso que se coloca uma série de questôes sobre as quais é preciso indagar. Assim, é conveniente conhecer e comparar o apoio que esses partidos têm tido em cada país. Também há que se estudar em que grau e como se modificaram os sistemas de partidos. Para realizar o estudo, adotamos a perspectiva do comparativismo clássico de Duverger, Blondel ou Sartori, que parte da análise do formato dos sistemas de partidos. Por isso entendemos, como apontou Mair (2011), que a mudança do número de partidos, ou seja, sua fragmentaçáo, assim como a polarizaçáo podem levar a uma modificação da maneira em que estes interagem, facilitando ou dificultando a governabilidade.

Aponta Mella (2012) que, em geral, as sociedades com uma cultura consensual sólida, com fortes tendências centristas, desenvolvem sistemas de partidos de caráter homogêneo, com formato bipartidário ou com multipartidarismo moderado. Em oposição, nas sociedades com alto nível de conflito e divisão e com grandes dificuldades para alcançar o consenso, ocorrem tendências centrífugas e se desenvolvem sistemas de partidos de caráter heterogêneo, com multipartidarismo polarizado, nos quais a governabilidade está dificultada. Na perspectiva dos partidos de extrema direita, podem se dar, portanto, duas situaçóes. A primeira é a sua integração completa e institucionalizada no sistema de partidos. Isto lhes permite sobreviver e ser aceitos na conformação dos blocos e para a formação de coalizóes eleitorais, legislativas ou de governo. A segunda é a rejeição por parte do restante dos partidos, mediante a criação de um "cordão sanitário" em torno deles, já que o eleitorado não aceita sua influência na definiçấo das políticas por seu caráter extremista. 
A fragmentação dos sistemas de partidos pode ser definida como o grau em que o apoio eleitoral ou a representaçáo parlamentar está dividida entre vários partidos. Para avaliar adequadamente a fragmentação dos sistemas de partidos, normalmente se utilizam diferentes índices, sendo o mais generalizado o de "número efetivo de partidos" elaborado por Laakso e Taagapera (1979), que é o que utilizamos neste trabalho em referência aos resultados eleitorais (NEPE).

Existem diversos argumentos para explicar a fragmentação. O principal é o de tipo institucional e se refere a como o sistema eleitoral, que é um mecanismo central na engenharia institucional (SARTORI, 2003), pode facilitar ou dificultar a entrada de novos partidos no sistema. Nesse sentido, é bem conhecido o ponto de vista de Duverger (1981), que, embora seja muito questionado a partir de diversas perspectivas (COLOMER, 2003; MILAZZO, MOSER e SCHNEIDER, 2018), afirma que o sistema proporcional produz fragmentação e multipartidarismo, enquanto o sistema majoritário produz bipartidarismo. Na Europa ocidental está generalizado o sistema proporcional, pelo qual a fragmentaçáo se acentuou com o tempo.

Outro argumento que justifica a fragmentaçáo dos sistemas de partidos é de tipo sociológico e se refere à perda de importância dos cleavages que tradicionalmente dão forma a um sistema de partidos, o que não significa seu desaparecimento (ROVNY e POLK, 2019). São mudanças produzidas na estrutura social e no comportamento dos grupos sociais (GOLDBERG, 2020). Assim, o desenvolvimento das classes médias e a expansão dos trabalhadores de colarinho branco desativaram em parte o voto de classe. Também a modernizaçáo das sociedades tem levado a uma mudança de vida em relaçáo às crenças religiosas e em relação às relaçôes entre o meio rural e o urbano. Concretamente, as tendências secularizadoras reduziram o peso do voto religioso. É por isso que os partidos tradicionais na Europa, social-democratas e democratas-cristãos, tem dificuldades para seguir contando com seus eleitores de sempre.

A isso somam-se as transformaçóes de tipo cultural que são consequência da mobilização cognitiva dos eleitores, graças a níveis mais altos de educação e o acesso a uma maior informação política. $\mathrm{O}$ resultado é o declínio da identificação partidária e o subsequente aumento de eleitores livres ou disponíveis, que se reflete em um incremento da volatilidade eleitoral e é o caldo de cultivo para a criação de novos partidos.

Um argumento mais técnico refere-se ao "efeito novidade", que não se apoia necessariamente na mudança social ou de valores, sequer dos cleavages. A novidade é em si mesma um projeto viável para um partido (SIKK, 2011). Seu fundamento é o 
descontentamento político (WUTTKE, 2020). Nesses casos, os novos partidos defendem um processo de purificação da política, e seu objetivo é convencer o eleitorado de que são melhores que os partidos velhos, por exemplo, na capacidade e integridade de seus dirigentes. Outro argumento técnico refere-se ao surgimento de issues ou questóes políticas que têm a ver com novas demandas sociais que utilizam e exploram de maneira estratégica os chamados "partidos-nicho" (MAGUID, 2005; BISCHOF, 2017). São questôes que não são incorporadas pelos partidos existentes em seus programas. Ambos os argumentos são de referência em relação aos novos partidos de extrema direita europeia, que operam, em boa medida, a partir da insatisfaçáo dos eleitores com os partidos preexistentes (KITSCHELT e MCGANN, 1995).

As mudanças nos sistemas partidários têm sido analisadas como um processo de "desalinhamento" dos eleitores ou de crescente independência a respeito dos partidos tradicionais e seus cleavages (GOLDBERG, 2020). Isso se expressa em um crescente abstencionismo ou, se é o caso, em um realinhamento, ou seja, na mudança do apoio de um partido a outro. Um alinhamento estável ocorre quando o apoio dos partidos existentes permanece inalterado durante longo tempo. Nesse caso, a maior parte dos eleitores escolhe um dos partidos existentes, a volatilidade eleitoral é baixa e não aparecem novos partidos. Mesmo que alguns mudem seu voto, a maioria apoia os partidos existentes. $\mathrm{O}$ desalinhamento implica a perda de identificação dos eleitores com os partidos e o aumento dos independentes. Um indicador disso é a elevada volatilidade eleitoral, e o outro é a aparição de partidos novos mal organizados. Isso implica uma falta de institucionalidade do sistema de partidos. Diz-se que há um realinhamento quando a mudança perdura. Esse realinhamento supóe necessariamente uma redistribuição do apoio aos partidos. Poder ser secular ou crítico. O primeiro supóe um processo gradual ao longo de várias eleiçóes, o segundo implica uma mudança em um período curto que modifica o mapa de partidos de modo permanente. O realinhamento supóe uma fase inicial de volatilidade eleitoral alta e outra posterior de redução dessa volatilidade. Em todo caso, pode ocorrer desalinhamento sem realinhamento (CARRERAS, MORGERNSTERN e SU, 2015).

$\mathrm{O}$ conceito de volatilidade eleitoral refere-se à mudança no comportamento dos eleitores entre eleiçóes, quer dizer, a mudança do apoio de uns a outros partidos. Para medi-la, se recorre geralmente ao índice de Pedersen, que segue a fórmula $V T=(a 1-$ $a 2)+(b 1-b 2)+(n 1-n 2) / 2$, sendo a1 a porcentagem de votos do partido a nas últimas eleiçôes, e a 2 nas eleições prévias. Ela tem em conta as mudanças de apoio eleitoral de cada partido em cada uma das eleiçôes consideradas. 
A polarização, segundo Sartori (1980, p. 161), é “[...] el ámbito general del espectro ideológico de cualquier comunidad política" e se refere à distribuição dos partidos na dimensão ideológica. É a distância ideológica dos partidos de um sistema. A polarização intensifica o debate ideológico e é também um indicador da capacidade de avaliação por parte dos indivíduos da atividade dos governantes. A polarização costuma levar ao conflito e ao protesto popular se é elevada, mas também permite uma melhor diferenciaçáo dos partidos e uma representação mais perfeita do eleitorado (WANG, 2014).

Para o estudo da polarizaçáo adotamos o ponto de vista da análise espacial referido e a incorporaçáo de preferências que contém os programas dos partidos políticos. Os partidos tratam de obter apoio dos eleitores aproximando-se do âmbito de suas preferências e oferecem políticas de acordo a elas. Para isso, formulam um programa eleitoral com objetivos e propostas que tratam de satisfazer às demandas dos eleitores.

Nessa perspectiva, se entende que existe uma estreita relação entre as políticas que promovem os partidos em seu programa e as ideologias. Concretamente, as propostas programáticas (as políticas) são um indicador ideológico para os cidadáos, porque toda ideologia contém uma representação de objetivos reais com medidas específicas para a ação. Por isso as ideologias são concebidas como um meio a que recorrem os partidos para alcançar o poder, já que podem ser utilizadas de forma racional pelos eleitores (DOWNS, 1957).

O ponto de partida desta análise é a distribuição dos eleitores desde a perspectiva ideológica em uma escala esquerda/direita e a ordenaçáo dos partidos na mesma escala, determinando a distância ideológica entre eles. Apesar da natureza do continuum esquerda/direita ter sido muito discutida, ele é considerado um meio para simplificar os conflitos políticos complexos e interpretado como uma imagem da posição dos partidos, ou seja, como uma mera ordenação em um espaço de competição. É um espaço no qual os partidos dirigem-se aos mesmos eleitores, que dá estrutura aos sistemas de partidos europeus (SCARROW, 2002; NOUSIAINEN, 2000; NARUD e STRØM, 2000; KNAPP, 2002; VERZICHELLI e COTTA, 2000).

Existem duas formas de avaliar a distância ideológica entre os partidos. Uma é atender às percepçóes que as elites têm a esse respeito, como os membros do parlamento ou os acadêmicos (exemplo o Chapel Hill Survey), e outra é estudar os programas eleitorais. Neste trabalho recorremos à segunda e analisamos o índice RILE do Manifesto Project (https:/manifesto-project.wzb.eu/). Para estudar a polarização dos 
partidos de extrema direita europeus, analisamos a incorporação de preferências, considerando em termos quantitativos a proximidade das posiçóes mais extremas da direita no âmbito espacial. Concretamente, avaliamos a porcentagem que cada programa dedica a favor das propostas dessa tendência.

A polarização não está vinculada necessariamente à fragmentação do sistema de partidos, já que são duas dimensões distintas. Segundo Sartori (1980), a fragmentação dificulta o funcionamento da democracia se (e somente se) expressa a existência de um sistema de partidos polarizado. Este caracteriza-se pela existência de partidos antissistema importantes, de oposições bilaterais mutuamente excludentes, que não podem somar suas forças porque se promove a competição centrífuga, se desenvolvem oposiçóes irresponsáveis e surge a política de superoferta ou de promessas excessivas típicas do populismo.

Tudo isto nos leva finalmente à consideraçáo da governabilidade de um país. Como nos regimes parlamentaristas europeus o Executivo depende da confiança na maioria parlamentar, existem dois aspectos concretos a serem considerados: um é a formação do governo, e o outro é sua estabilidade, medida pelo tempo de sua permanência. Entendemos com Mair (2011) que a mudança de um sistema de partidos pode modificar o modelo de competição partidária, o que afeta a forma em que se produz o acesso ao governo de um partido ou coalizáo e a maneira em que se dá a alternância entre partidos. Mais precisamente, a elevada fragmentação e polarização de um sistema de partidos pode afetar a governabilidade, dificultando a formação de governos e condicionando sua estabilidade.

Neste trabalho comparamos quatorze sistemas de partidos europeus nos quais a extrema direita tem relevância a nível institucional e, mediante análise estatística descritiva, avaliamos as tendências resultantes e seus efeitos sobre os sistemas de partidos. Identificamos os partidos através das análises acadêmicas por seus conteúdos programáticos e por seu vínculo com grupos de instituiçóes internacionais, como o Parlamento Europeu. O ponto de partido desta análise é o apoio eleitoral que estes partidos têm obtido ao longo do século XXI (Tabela 1), apesar de termos em conta a perspectiva histórica. 
144 | Manuel Sánchez de Dios

Tabela 1 - Porcentagem de voto da extrema direita na Europa por países (1999-2019)

\begin{tabular}{|c|c|c|c|c|c|c|c|c|c|c|c|c|c|c|c|c|c|c|c|}
\hline & 1999 & 2001 & 2002 & 2003 & 2005 & 2006 & 2007 & 2008 & 2009 & 2010 & 2011 & 2012 & 2013 & 2014 & 2015 & 2016 & 2017 & 2018 & 2019 \\
\hline França & & & 12,1 & & & & 4,7 & & & & & 13,6 & & & & & 13,2 & & \\
\hline Suíça & 26,2 & & & 26,7 & & & 28,9 & & & & 26,6 & & & & 29,4 & & & & 25,6 \\
\hline Itália & & 15,9 & & & & 16,9 & & 8,3 & & & & & 6,1 & & & & & 21,7 & \\
\hline Áustria & 26,9 & & 10 & & & 11,4 & & 27,5 & & & & & 20,5 & & & & 26 & & 16,1 \\
\hline Bélgica & 11,4 & & & 13,4 & & & 15,9 & & & 10 & & & & 3,8 & & & & & 11,9 \\
\hline Holanda & & & 17 & 5,7 & & 6,2 & & & & 16 & & 10,1 & & & & & 14,9 & & \\
\hline Dinamarca & & 12,5 & & & 13,3 & & 13,9 & & & & 12,3 & & & & 21,1 & & & & 11,9 \\
\hline Finlândia & 1 & & & 1,6 & & & 4,1 & & & & 19,1 & & & & 17,6 & & & & 17,4 \\
\hline Noruega & & 14,6 & & & 22,1 & & & & 22,9 & & & & 16,3 & & & & 15,2 & & \\
\hline Alemanha & & & & & 1,6 & & & & 1,5 & & & & 4,7 & & & & 12,6 & & \\
\hline Suécia & & & & & & & & & & 5,7 & & & & 12,8 & & & & 17,5 & \\
\hline RU & & & & & 2,2 & & & & & 3,1 & & & & & 12,6 & & 1,8 & & \\
\hline Grécia & & & & & & & 3,8 & & 5,6 & & & $6,9^{*}$ & & & $7^{*}$ & & & & 6,6 \\
\hline Espanha & & & & & & & & & & & & & & & & 0,2 & & & $15,1^{*}$ \\
\hline
\end{tabular}

* Das eleiçóes celebradas no mesmo ano utiliza-se a porcentagem mais elevada.

Fonte: Elaboração própria.

\section{Comparação de casos}

No estudo agregado consideramos cinco variáveis explicativas. As três primeiras estão relacionadas com a fragmentação. São a evolução do apoio eleitoral, as mudanças no número efetivo de partidos e a volatilidade eleitoral e o realinhamento do eleitorado. A quarta está relacionada com a polarizaçáo, e nela consideramos o posicionamento dos partidos no eixo esquerda/direita (índice RILE) e a relevância dos diferentes issues nos programas eleitorais. Finalmente, consideramos a variável da governabilidade.

\section{Identificação dos partidos de extrema direita europeus do século XXI}

$\mathrm{Na}$ maior parte dos casos do Quadro 1, a porcentagem de votos corresponde a apenas um partido, porém, em outros, são vários os partidos que têm representação parlamentar, portanto deve-se identificar os partidos de extrema direita em cada país.

$\mathrm{Na}$ Alemanha o partido Alternativa pela Alemanha (Alternative Für Deutschland, AfD), acedeu ao Bundestag em 2017, poucos anos depois de entrar na disputa. Se trata de um fenômeno muito recente cuja importância é difícil de avaliar. $\mathrm{Na}$ Áustria, o Partido da Liberdade (FPO), que tem representação desde as primeiras eleiçôes do pós-guerra, foi incrementando seu apoio eleitoral desde 1986. Na Bélgica, dois partidos de extrema direita, o Bloco Flamengo (Vlaams Bloc-VB) e a Frente Nacional (Front Nationale - FN), obtiveram relevância no final dos anos 1980 - o primeiro no norte do país e o segundo no sul, embora este último não tenha alcançado a capacidade organizativa, de liderança e de êxito eleitoral que tem o primeiro (DESCHOUVER, 2002). Outros pequenos partidos de extrema direita, como a Lista Decker, obtiveram certo apoio em Flandres entre 2007 e 2014. O VB foi renomeado 
em 2004 como Vlaams Belang (Interesse Flamengo) depois do partido ter sido condenado por racismo.

O Partido Popular Dinamarquês (Dansk Folkeparti, DF), que é um partido de tamanho médio (DAMGAARD, 2000), alcançou representação parlamentar na Dinamarca na passagem do século. Na Espanha, o partido Vox conseguiu um limitado apoio eleitoral em 2016. Após uma ascensão rápida, chegou a conseguir 52 assentos nas eleiçóes de novembro de 2019. Na Finlândia, surgiu um partido de extrema direita com a mudança do século, chamado os Verdadeiros Finlandeses (Perussuomalaiset, PS), que agora é conhecido como Partido Finlandês. Na França, a Frente Nacional (FN) surgiu na década de 1970 como herdeira de uma cultura política de extrema direita fascista originada em torno da figura de Poujade, nos anos 1960. Na Grécia, o partido União Popular Radical - LAOS obteve representação parlamentar em 2007. Mais tarde, dois partidos dessa tendência entraram no parlamento em maio de 2012: Aurora Dourada, com 6,9\% dos votos, e Gregos Independentes - ANEL, com 10,6\%.

$\mathrm{Na}$ Holanda a List Pym Fortuyn (LPF) foi o partido mais votado em 2002, alcançando $17 \%$ dos votos. A causa disso foi o assassinato de seu dirigente nove dias antes da eleição (LUCARDIE, 2003). Uma excisão de 2006 chamada Partido pela Liberdade (PVV) desde entáo consegue o apoio da maior parte desse setor do eleitorado, mesmo que ocasionalmente apareçam outros pequenos partidos - como o Fórum pela Democracia, em 2017 - que conseguem assentos no parlamento.

Com a transformação do sistema de partidos na Itália em 1990 surgiu a Aliança Nacional, herdeira do partido fascista Movimento Social Italiano. Ela teve uma importante representação parlamentar até 2008. Também surgiu a Liga Norte (agora A Liga). No século XXI apareceu um pequeno partido chamado Irmãos da Itália, que obteve 4,3\% dos votos em 2018. Nesses anos também surgiu o Movimento 5 Estrelas, partido populista não radical e de difícil tipificação programática no eixo esquerda/direita (MOSCA e TRONCONI, 2019), embora tenha feito parte do grupo Liberdade e Democracia Direta da VIII legislatura do Parlamento Europeu juntamente com o britânico UKIP.

Na Noruega, o Partido do Progresso (FRP), fundado em 1973 como um "partido-nicho" anti-impostos, conseguiu uma posiçáo relevante a partir de 1989, sendo a segunda força parlamentar em 1997, 2005 e 2009. No Reino Unido (RU), o Partido pela Independência do Reino Unido ( $U K$ Independence Party, UKIP) apareceu na primeira década do século XXI com 17,5\% dos votos, porém, devido ao sistema eleitoral, obteve apenas uma cadeira no parlamento. Na Suécia, o partido dos 
Democratas Suecos (Sverigedemokraterna, SD) foi fundado em 1988, e nas eleiçóes de 2018 obteve 62 cadeiras no parlamento. Na Suíça, o Partido Popular Suíço, anteriormente chamado União Democrática de Centro (UDC), foi fundado em 1971 a partir dos interesses agrários e de meios comerciais (LAUVAUX, 1990). Com o tempo, tornou-se o primeiro partido da Suíça.

\section{Evolução do apoio eleitoral dos partidos}

Os partidos de extrema direita estiveram presentes em muitos países europeus depois da Segunda Guerra Mundial, mesmo com um apoio eleitoral muito baixo, de menos de $5 \%$ dos votos, e somente obtiveram representaçáo institucional na Itália, Áustria e Finlândia na década de 1960. Nos anos 1970, Suíça, Dinamarca e Bélgica tiveram também partidos de extrema direita em seus parlamentos, mas somente na Suíça e na Dinamarca superavam $10 \%$ dos votos, enquanto na Itália, Finlândia e Áustria chegavam a 7\%. Em suas origens, esses partidos tinham a característica de serem partidos de defesa de setores sociais minoritários, como agricultores, comerciantes e pequenos proprietários na maior parte dos casos, embora na Itália ou França estivessem vinculados às tendências populistas de tipo fascista que estimulavam o racismo e a xenofobia (MACRIDIS, 1992). Em meados dos anos 1980, o apoio eleitoral da extrema direita aumentou na França, Itália, Áustria e Noruega, onde, junto com a Suíça, superavam amplamente $10 \%$ dos votos. Com a mudança de século, incrementou-se surpreendentemente o voto na extrema direita nesses países.

No século XXI produziu-se a maior expansão da extrema direita na Europa Ocidental e, como acabamos de apontar, houve um aumento de seu apoio nos países onde estava estabelecida. $\mathrm{O}$ processo mais expansivo ocorreu na segunda década do século, quando, na Itália, e Áustria, a extrema direita alcançou níveis em torno de 25\% dos votos, e na Finlândia, Noruega, Suíça, Holanda e Dinamarca, em torno de 15\%. Entretanto, o mais importante é que esses partidos surgem e se estabelecem como partidos "novos" nos sistemas do Reino Unido, Suécia, Holanda, Grécia, Alemanha e Espanha. Nos dados sobre apoio eleitoral do Quadro 1, observa-se um processo de decadência de alguns casos ao final do período. Isso ocorreu no Reino Unido, pois o partido UKIP acabou sendo o reflexo de uma situação muito conjuntural, o Brexit. Também na Áustria, Dinamarca, Suécia, Noruega e Grécia produziu-se uma redução do apoio. 
Esses partidos geralmente superam os $10 \%$ dos votos, mas em poucos países alcançaram mais de $20 \%$. E, quando isso ocorreu, foi em poucas ocasiôes, embora na maior parte dos países tenham se aproximado dessa porcentagem.

Alguns partidos chegaram a ser a primeira força parlamentar, concretamente na Itália em 2013 e 2018 e na Suíça desde 1999. Mais frequentemente, eles têm sido a segunda força parlamentar, como na Dinamarca em 2015, na Áustria em 1999, na Holanda em 2002 e 2017, Noruega em 1997, 2005 e 2009 e na Finlândia em 2015 e 2019. Isso se deve ao fato de que, nesses países, há uma alta fragmentação do sistema de partidos.

Se considerarmos a evoluçáo do apoio eleitoral desses partidos desde 1990 até 2020, observamos que a linha de tendência é ascendente em quase todos os casos. Se circunscrevermos a análise da tendência exclusivamente ao século XXI (Quadro 3), comprova-se que em geral as linhas de tendência são ascendentes, salvo na Bélgica. $\mathrm{Na}$ Suíça e na Áustria foram moderadamente ascendentes. Isso quer dizer que o apoio geral à extrema direita na Europa se mantém em uma fase de crescimento e expansão, devido ao fato de os partidos estarem se institucionalizando.

\section{A mudança do número de partidos e seus efeitos}

$\mathrm{O}$ indicador mais relevante da fragmentação dos sistemas de partidos é o número efetivo de partidos (NEP). Neste trabalho consideramos o NEP eleitoral (NEPE) porque permite afinar a análise da importância real dos partidos. Geralmente, na maior parte dos casos, a tendência é o incremento do índice, tanto tomando a série desde 1990 como somente a do século XXI. Na longa série, observa-se que o NEPE tem uma redução na mudança do século, particularmente na Itália, França, Noruega, Suíça e Holanda. Logo aumenta, e o principal incremento produz-se ao final da segunda década do século. Portanto, o formato multipartidário generalizado na Europa acentuou-se. As exceçóes são Itália, onde o NEPE caiu em relação a 1990 devido à mudança do sistema de partidos nessa data, o Reino Unido, onde o NEPE voltou à sua posição inicial depois da perda de apoio eleitoral do UKIP (WEBB, 2002a), e Grécia, que também tem uma redução do NEPE uma vez superada a crise política de 2012, quando chegou a nove partidos nas eleiçóes de maio desse ano.

Se considerarmos as linhas de tendência do NEPE no período de 1990 até 2020, há somente três casos com tendência descendente: Suíça, Itália e Reino Unido; os demais têm tendência ascendente. O caso da Suíça deve-se ao fato de que o país teve um NEPE mais elevado nos anos 1990. Entretanto, não foi em todos os casos que o 
incremento do NEPE se deveu ao incremento do apoio aos partidos de extrema direita. Assim, na Suíça, Bélgica e Dinamarca e nos casos de Grécia, Espanha, França e Finlândia, o incremento se deve também à aparição de outros partidos como verdes, liberais ou de extrema esquerda (DESCHOUVER, 2002).

Como indicado acima, a fragmentaçáo dos sistemas de partidos depende do sistema eleitoral, e na Europa está generalizada a regra proporcional. Esta reduz o custo eleitoral para aceder aos parlamentos, mas alguns países têm mecanismos de correção da proporcionalidade. Concretamente na Alemanha e Espanha, a lei eleitoral exige alcançar um mínimo de 5\% e 3\% dos votos respectivamente para obter um assento. Como afirma Saalfeld (2000), esse mínimo está pensado para limitar o número de partidos nas câmaras e facilitar a governabilidade. Na Itália e na Grécia são incluídos critérios majoritários de distribuição de cadeiras para favorecer uma sobrerrepresentação dos partidos vencedores, com o objetivo de promover governos com maiorias sólidas. Na Europa existem dois países com sistemas majoritários, Reino Unido e França, nos quais a extrema direita sempre teve dificuldades para aceder ao parlamento, mesmo com um elevado apoio eleitoral. Assim, a Frente Nacional (FN) francesa obteve 35 deputados em 1986 com um sistema eleitoral proporcional e 10\% dos votos. No entanto, obteve representação parlamentar de um deputado em 1988 e 1997, dois em 2012 e oito em 2017 com o sistema majoritário tradicional e um apoio eleitoral próximo dos $14 \%$. O UKIP britânico obteve bons resultados eleitorais em 2015, com 17,5\% dos votos, mas apenas uma cadeira. Pela perspectiva institucional é importante destacar que a França é o único caso na Europa de regime semipresidencial, no qual a eleição do Presidente da República tem um grande valor para avaliar a força da extrema direita. Assim, a FN chegou ao segundo turno das eleiçôes presidenciais em duas ocasiōes, em 2002 e 2017; nessa última eleição obteve 34\% dos votos.

O principal efeito da mudança do NEPE foi um aumento do pluralismo, dado que aumentou o NEP parlamentar, pois ambos evoluíram paralelamente. Isso é especialmente claro em relação aos sistemas de partidos nórdicos, onde o modelo tradicional se modificou com o surgimento da extrema direita, passando a uma média de cinco grupos parlamentares de tipo médio, entres os quais se formam as coalizóes legislativas (SUNDBERG, 2002; NARUD e STRØM, 2000; DAMGAARD, 2000). Aqui houve um reforço da competição partidária no eixo esquerda/direita, mas produzindo um multipartidarismo moderado.

O êxito eleitoral da extrema direita alterou relativamente o sistema de partidos da Bélgica, pois produziu-se no marco de uma competição partidária baseada no eixo 
linguístico/regional de tipo centrífugo (DE WINTER, TIMMERMANS e DUMONT, 2000). Tampouco na Holanda a extrema direita modificou a competiçáo multipolar histórica do sistema de partidos (TIMMERMANS e ANDEWEG, 2000). No Reino Unido, não foi afetada a estrutura tradicional bipartidária, nem na Suíça se alterou a estrutura altamente fragmentada do sistema de partidos, que é muito estável (FERRER, 2014).

Contudo, na Áustria o desenvolvimento da extrema direita teve o efeito de produzir a "desconcentração" do sistema de partidos (MULLER, 2000), o que pode ser representativo de outros casos. Aqui os principais partidos, o Partido Socialista Austríaco (SPO) e o Partido Popular Austríaco (OVP), de caráter democrata cristão, concentravam em torno de $90 \%$ dos votos e dos assentos, mas tudo mudou desde 1986 com a ascensão eleitoral do Partido da Liberdade (FPO). Algo parecido ocorreu na Grécia, Espanha e Alemanha, embora não somente pelo apoio eleitoral da extrema direita. Tanto na Grécia como na Espanha, o modelo tradicional mudou por uma desconcentração do voto. $\mathrm{Na}$ Espanha, o aumento do pluralismo modificou o modelo de "bipartidarismo imperfeito" baseado na alternância de dois partidos de centroesquerda e centro-direita (HERNÁNDEZ e LAIZ, 2017), enquanto na Grécia o sistema de "dois partidos e meio" se desconcentrou pelo quase desaparecimento do partido socialista.

$\mathrm{Na}$ França e na Itália os partidos de extrema direita têm condicionado a estrutura de blocos a partir dos quais constroem-se as coalizóes. Na França, a expansão do voto a favor da FN reforçou a competiçáo partidária do eixo esquerda/direita (THIÉBAULT, 2000) porém com mais intensidade dentro do bloco de direita, no qual a FN se apresenta como um partido antissistema (KNAPP, 2002). Na Itália os partidos de extrema direita também reforçaram a competição no eixo esquerda-direita, e não se integraram em coalizóes eleitorais, apesar de que, como veremos abaixo, participam nas coalizóes de governo (VERZICHELLI e COTTA, 2000).

\section{A volatilidade eleitoral e o realinhamento do eleitorado}

Em todos os casos, observa-se que o apoio aos partidos de extrema direita está estreitamente ligado a um aumento da volatilidade eleitoral, que é uma consequência lógica da mudança no voto dos eleitores. Porém, não em todos os casos a volatilidade está apenas ligada ao apoio a esses partidos, pois influi também a abstenção, além do voto em outros partidos (GOLDBERG, 2020). Exemplos nesse sentido são a França, onde a esquerda e os ecologistas também melhoraram sua participação na distribuição 
dos votos; na Grécia houve a ascensão do Syriza, de extrema esquerda; na Espanha a volatilidade está vinculada ao surgimento de novos partidos em eleiçóes anteriores ao surgimento da extrema direita. Na Bélgica e na Holanda ocasionalmente aparecem pequenos partidos de extrema direita mal organizados (BEYEMS, LUCARDIE e DESCHOUVER, 2016).

$\mathrm{Na}$ Europa está bastante generalizada a tendência a um aumento da volatilidade eleitoral desde os anos 1990 e de uma maneira mais precisa no século XXI, porém é necessário fazer algumas distinçóes. Concretamente na Holanda, Noruega, Suíça e Bélgica, a tendência, desde os anos 1990, é descendente, apesar de que no século XXI é plana na Bélgica; na Finlândia é plana desde os anos 1990, mas levemente ascendente no século XXI. Esses dados são os que nos permitem avaliar o realinhamento dos eleitores.

Com a mudança de século, produziu-se o desalinhamento mais generalizado do eleitorado por um claro aumento de apoio aos partidos de extrema direita. Isso ocorreu na Áustria, Bélgica, Dinamarca, Itália, Noruega e Suíça. É necessário considerar que os processos de desalinhamento às vezes ocorrem em duas fases. Por exemplo, já houve um movimento com essas características nos anos 1970 na Dinamarca e Finlândia, e nos anos 1990 na França, Itália e Noruega. Outro processo importante de desalinhamento pelo apoio à extrema direita ocorreu na segunda década do século XXI, concretamente na Alemanha, Áustria, Bélgica, Dinamarca (onde acentuou-se), Finlândia, Holanda, Reino Unido (de tipo conjuntural), Suécia e Espanha.

Ao relacionar o processo de desalinhamento com a tendência de volatilidade eleitoral e o volume de apoio aos partidos, podemos avaliar os processos de realinhamento dos eleitores em torno dos partidos de extrema direita. Dos dados obtidos, observamos oito casos com um processo claro de realinhamento que manifestam um voto estável a favor dos novos partidos de extrema direita. São os da Áustria, Dinamarca, Finlândia, França, Holanda, Itália, Noruega e Suíça. No caso de Finlândia e Holanda, esse realinhamento se produziu no século XXI e se aproxima do tipo crítico, enquanto na Áustria, França, Dinamarca, Noruega e Suíça se observa um crescimento sustentado da extrema direita ao longo do tempo e é, portanto, um realinhamento secular. Na Itália, o processo não é totalmente linear pelo pluralismo de partidos de extrema direita que se sucederam ao longo do tempo, e é por isso que se observa uma elevada volatilidade desde a década de 1990. Ou seja, na Itália houve um processo de realinhamento dos eleitores nos anos 1990 e outro de realinhamento dos 
partidos de extrema direita na segunda década do século XXI. Aquele pode ser considerado de caráter secular a favor da NA e da LN, e este é de caráter impreciso após o desaparecimento da AN. Na Suécia, a tendência ascendente de apoio eleitoral ao SD e o volume que este obteve, vinculado ao aumento da volatilidade, permitem pensar que está ocorrendo um processo de realinhamento crítico na segunda década do século XXI.

Nos demais casos, não se pode falar de realinhamento porque somente se dá uma situação de apoio conjuntural à extrema direita, mesmo que em diferentes situaçôes particulares. $\mathrm{Na}$ Bélgica houve um processo de realinhamento a favor da extrema direita com a mudança de século, mas com um desalinhamento posterior e, embora nas eleiçóes de 2019 ela tenha voltado a obter êxito, a tendência é decrescente com uma volatilidade plana ou estabilizada. No Reino Unido, a existência do UKIP deve-se a que os partidos tradicionais não tiveram uma posição bem definida em relação à issue do Brexit até a realizaçáo do referendo. O caso da Grécia é similar ao do RU no sentido de que o apoio à extrema direita cresceu e se reduziu em um período de tempo muito limitado, que é o da crise política derivada da crise econômica. De fato, ANEL é um partido-nicho antiausteridade. Em todo caso, deve-se ter em conta que o apoio à extrema direita na Grécia é bastante reduzido, em torno de $6 \%$ dos votos. Os casos de Alemanha e Espanha são diferenciáveis porque a extrema direita cresce em um período eleitoral breve e muito recente (com elevada volatilidade), em que é difícil definir uma tendência de médio prazo para falar de realinhamento crítico.

\section{Os posicionamentos no indice RILE e os conteúdos programáticos}

Através dos dados do Manifesto Project avaliamos o grau de polarização dos partidos considerando, de um lado, seu posicionamento no eixo esquerda-direita em cada menção eleitoral no índice RILE e, por outro lado, a forma com que consideram as grandes questôes programáticas. Para isso, se pesquisa de maneira quantitativa a atenção que dedica um programa a cada uma das issues de um dicionário predeterminado. Isso nos permite, também, ver o vínculo dos partidos com os cleavages tradicionais e, se for o caso, sua natureza de partidos-nicho.

A respeito do posicionamento no índice RILE, se observa que, no conjunto dos países, os partidos adotaram as propostas mais extremas no começo da década de 1990 e em meados da primeira década do século. Este último é um momento em que, salvo na Suíça, todos os partidos perderam apoio eleitoral. Mais tarde, deu-se uma 
progressiva moderação ao longo da segunda década, alguns partidos inclusive chegando a incorporar propostas de centro-esquerda. Nessa etapa houve uma recuperaçáo do apoio eleitoral.

As linhas de tendência de polarização no século XXI são ascendentes na Áustria e Grécia e levemente ascendentes na Dinamarca, Holanda e Finlândia - ainda que, neste último caso, a polarização seja próxima a zero, ou seja, muito baixa. Isso se combinou com uma tendência de voto levemente ascendente, embora na Finlândia seja muito ascendente. A polarização é descendente na Bélgica, França, Noruega, Alemanha, Itália, Suíça e Suécia. Neste último país, é muito baixa, próxima a zero. Nos últimos quatro casos, a polarização se combina com uma tendência de voto ascendente (Quadro 1). Em resumo, no conjunto de países, se observa uma tendência geral de limitar ou reduzir os posicionamentos extremos desses partidos com o objetivo de ampliar sua base eleitoral no centro do espaço ideológico. Em outros termos, os partidos buscam aproximar suas posiçóes do número zero no índice RILE (Tabela 2).

Tabela 2 - Índice RILE de polarização dos partidos da extrema direita por países entre 1999 e 2019

\begin{tabular}{l|l|l|l|l|l|l|l|l|l|l|l|l|l|l|l|l|l|l}
\hline & 1999 & 2001 & 2002 & 2003 & 2005 & 2006 & 2007 & 2008 & 2009 & 2010 & 2011 & 2012 & 2013 & 2014 & 2015 & 2017 & 2018 & 2019 \\
\hline França & & & 1,7 & & & & 1,6 & & & & & 3,6 & & & & 2,2 & & \\
\hline Súça & 26,6 & & & 41,1 & & & 43,1 & & & & 0,8 & & & & 35,2 & & & \\
\hline Itália & & 18,6 & & & & 48,2 & & $-3,7$ & & & & & 3,8 & & & & 4,6 & \\
\hline Áustria & 24,6 & & -18 & & & $-3,5$ & & $-8,7$ & & & & & 20,5 & & & 9,2 & & \\
\hline Bélgica & $-2,9$ & & & $-2,9$ & & & 24,5 & & & 39,4 & & & & 17,3 & & & & 9,2 \\
\hline Holanda & & & 14,9 & 3,2 & & 38,6 & & & & 13,2 & & 15,6 & & & & 20 & & \\
\hline Dinamarca & & 35 & & & 38 & & 14,8 & & & & 30,9 & & & & 18,7 & & & s/d \\
\hline Finlândia & $-5,8$ & & & $-5,8$ & & & $-6,5$ & & & & 0,4 & & & & $-4,9$ & & & \\
\hline Noruega & & 23,9 & & & 16,9 & & & & 6,7 & & & & $-1,9$ & & & 14,1 & & \\
\hline Alemanha & & & & & & & & & & & & & $-2,3$ & & & 17,4 & & \\
\hline Sú́cia & & & & & & & & & & 15,6 & & & & $-6,6$ & & & $-9,1$ & \\
\hline RU & & & & & & & & & 35 & & & & & $-7,7$ & 2 & & \\
\hline Grécia & & & & & & & & & & & & & & & & & & \\
\hline Espanha & & & 1,7 & & & & 1,6 & & & & & 3,6 & & & & 2,2 & & \\
\hline
\end{tabular}

Leitura: direita de 0 a 100 (positivo); esquerda 0 a -100 (negativo).

Fonte: Elaboração própria a partir dos dados do Manifesto Project (<https://manifestoproject.wzb.eu/>).

No que diz respeito aos conteúdos dos programas, os dados do Manifesto Project permitem, por um lado, diferenciar entre os casos e, por outro, dar precisão às propostas confusas que elaboram os partidos de extrema direita europeia desde finais do século XX, nas quais, como apontam Gallaher, Laver e Mair (1992), se misturam issues contemporâneas com uma variedade heterogênea de propostas no âmbito das políticas atuais (meio ambiente, desenvolvimento de infraestrutura). Também permitem comprovar seu caráter antissistema, assim como sua conexão com as atitudes 
racistas e xenófobas e com a desilusão dos cidadãos com a política, que parece ser o que promove seu crescimento eleitoral.

No estudo, observa-se que o tema mais importante para esses partidos é o Estado de bem-estar, ao qual se dá um apoio generalizado muito alto, assim como à sua expansão, sobretudo no século XXI. Ou seja, nesses partidos existe uma clara preocupação pela defesa dos sistemas de saúde, das aposentadorias e do cuidado dos idosos, assim como o cuidado da infância e da moradia. É um tema com elevada valorização nos programas dos partidos da Áustria (desde os anos 1990), Bélgica, Dinamarca, Finlândia, Suécia e Reino Unido. Essa questão tem uma alta valorização na Suíça, Itália, Holanda, Alemanha e Grécia. Somente na França carece de valorização relevante e só teve alguma importância no programa das eleiçôes de 2012. Também se defende nos programas em geral, embora com menos contundência, o crescimento da igualdade. Isso é mais importante para os partidos da Finlândia e Dinamarca. Se valoriza um pouco menos a defesa da educação e da cultura, que é mais importante na Suécia, Dinamarca e Bélgica.

É na defesa dessas issues que se produz a aproximação no centro do índice RILE entre os partidos europeus, e é a base para se construir o consenso de centro que menciona Ferrera (2014). No entanto, é necessário considerar que a defesa do Estado de bem-estar dos partidos de extrema direita baseia-se em um "nativismo da política social” (ENNSER-JEDENASTIK, 2018) que discrimina os imigrantes nos auxílios sociais. É o chamado welfare chauvinismo, que foi identificado há algum tempo como um traço característico e relevante nos programas desses partidos (ANDERSEN e BJØRKLUND, 1990; KITSCHELT e MCGANN, 1995; SCHUMACHER e VAN KERSBERGEN, 2016).

Outra questão que tem um apoio geral muito alto é a defesa da lei e da ordem. Isso supóe favorecer a expansão dos serviços de política, justiça e a segurança interna do país, que são temas tradicionais do pensamento conservador (GALLAHAER, LAVER e MAIR, 1992) e que promovem um sentido autoritário. Tal tema tem valorização muito alta no Reino Unido, Suécia, Dinamarca, Bélgica e Áustria. Tem alta valorizaçáo na Finlândia, Holanda e França e um pouco menos nos partidos da Itália. Complementar a isso é uma valorização bastante alta do nacionalismo. Este é um componente central do ideário fascista clássico (ANTÓN e RUIZ, 1998) e segue sendo chave para a extrema direita do nosso tempo (MACRIDIS, 1992). Concretizase em um apelo ao patriotismo, à defesa das ideias nacionais estabelecidas, ao orgulho da cidadania ou de pertencimento à comunidade nacional, o nativismo em termos de 
Mudde (2007) e o repúdio de qualquer forma de subversão. Isso se conecta em muitos casos com a consciência cívica vinculada à defesa da sociedade civil e do interesse público, e inclusive com a defesa da democracia. O nacionalismo é altamente valorizado pelos partidos da França, Alemanha, Finlândia, Suécia e Reino Unido e um pouco menos pelos da Grécia, Áustria e Bélgica. No entanto, essa issue não é relevante para a extrema direita dinamarquesa, holandesa, italiana, norueguesa ou suíça. Isso diferencia a direita radical do século XXI do fascismo "ultranacionalista" ao qual se refere Griffin (2019).

A imigração é outra issue que interessa de maneira relevante a maior parte dos partidos. O interesse crescente por ela está vinculado ao crescimento da população imigrante e, de maneira precisa, ao dos próprios partidos de extrema direita (GREENPEDERSEN e OTJES, 2019). A nível programático, essa questáo concretiza-se em diversos aspectos, como no repúdio ao multiculturalismo, particularmente nos partidos da Suécia, Finlândia, Holanda e Bélgica e, em menor medida, nos da Suíça, França e Reino Unido. Há também uma alta rejeição às políticas de integração, salvo na Suíça e, em consequência, se promove uma defesa da homogeneidade cultural das sociedades. Isso está de acordo com as análises realizadas sobre o tema por Westlake (2018). Por outro lado, a assimilação dos imigrantes é defendida com muita intensidade na Alemanha, Suécia, Finlândia, Dinamarca, Holanda e em menor medida na França e Áustria. Entretanto, deve-se destacar que a xenofobia frente ao imigrante não é um tema explicitado nos programas, embora seja conhecido há muito tempo, através dos meios de comunicação, em alguns casos, como o da Frente Nacional francesa, do Partido do Progresso dos anos 1990 e do Partido da Liberdade austríaco (MACRIDIS, 1992). Essa não explicitação é devida a uma tentativa de evitar a condenação judicial por racismo, como aconteceu com o VB belga em 2004, ou a uma estratégia de moderação do discurso para a formação de coalizóes de centro-direita (GREENPEDERSEN e OTJES, 2019).

Os partidos de extrema direita apoiam em geral, embora de forma moderada, a moralidade tradicional. Nos partidos da Finlândia e Alemanha, essa questão tem uma valorização muito alta; nos da França e Grécia, se valoriza um pouco menos, e ainda menos nos da Suécia, Dinamarca, Bélgica, Áustria e Itália. Isso caminha lado a lado com a defesa da família tradicional, das instituiçóes religiosas e o repúdio ao comportamento imoral ou inapropriado.

Um tema que a maioria dos programas tem em consideração, atribuindo a ele alta valorização, é a proteção do meio ambiente, embora não seja relevante nos partidos 
da França, Alemanha ou Suécia. Isso supõe a defesa da preservação dos recursos naturais, do meio rural e dos bosques, dos parques naturais e dos animais. Outra questão de importância pelo número de partidos que a tem em consideração é a rejeiçâo manifesta à União Europeia, que é muito elevada no caso do UKIP britânico e do partido alemão AfD, embora não seja um tema de interesse especialmente nos partidos da Áustria, Dinamarca ou Grécia, enquanto na Itália não houve uma oposição declarada.

No âmbito econômico, quando houve manifestação programática expressa, deu-se uma valorização alta da economia de mercado, que é um fator de polarização (JANKOWSKI, SCHNEIDER e TEPE, 2017). Isso ocorre nos programas dos partidos da Suíça, Holanda, Alemanha, Dinamarca, França e Grécia; apesar de que também tem alta valorização a intervenção do Estado em pelo menos três casos: Itália, Finlândia e Alemanha. Com uma valorização menor aparece o apoio à regulação econômica nos programas de partidos da Alemanha, Suíça, França, Bélgica e Holanda. O objetivo é a proteção dos consumidores, a prevenção dos monopólios e a defesa das pequenas empresas. Uma porcentagem alta valoriza, embora com menor relevância, a ortodoxia econômica, ou seja, a redução dos déficits fiscais, os recortes em caso de crises, a defesa dos mercados e do sistema bancário e uma moeda forte. Essa issue é importante para os partidos da Suíça, Grécia, Itália, Bélgica e Dinamarca.

Outro âmbito que tem relevância para os partidos é a eficiência do governo e da administração, que é outra política tradicional dos conservadores. Essa não é uma issue muito atual nos programas, pois nos partidos da Dinamarca e Áustria teve mais relevância com a mudança do século. Tem alguma relevância nos programas dos partidos da Itália, Reino Unido, Holanda e um pouco menos na Suíça e Alemanha. O tema da corrupção também está presente nos programas com uma relevância médiaalta. Tem sido particularmente importante na Grécia, Bélgica e Itália, e menos relevante na Holanda e Alemanha. Nos outros casos não tem importância.

Os partidos mostram apoio e interesse pelos trabalhadores somente em alguns países; é alto nos partidos da Áustria, Bélgica e Suécia e baixo nos da Finlândia, Reino Unido e Grécia, o que mostra uma certa vinculação ao cleavage capital/trabalho, mas de pouca transcendência eleitoral. Também existe um apelo aos interesses dos agricultores e fazendeiros nos partidos de um pequeno grupo de países, já que alguns deles tiveram sua origem no meio rural. $\mathrm{O}$ federalismo é um tema muito importante em alguns casos, como o da Bélgica, onde o principal partido de extrema direita é o nacionalista flamengo, e também na Liga Italiana. Por último, é necessário apontar 
uma ausência programática importante nos partidos de extrema direita, que é a política de gênero, que apenas recentemente está sendo incorporada a seus programas (ERZEEL e RASHKOVA, 2017).

Em resumo, ao analisar as issues mais relevantes, observa-se que existe uma clara conexão programática com o conservadorismo, embora nesses partidos não se dê muita ênfase ao apoio à empresa privada ou à austeridade fiscal, mas sim às questóes de lei e ordem, eficiência do governo e moralidade tradicional. Também existe um vínculo estreito com o nacionalismo. Em geral não ocorre uma relação de apoio ao exército ou ao incremento do gasto militar, salvo em alguns casos como o do grego ANEL. Um dado relevante é que em todos os partidos existe um grau de moderaçáo programática que se manifesta na defesa do Estado de bem-estar, embora vinculado a uma proposta "nativista". Em geral, nesses partidos, existe uma clara desconexáo com os cleavages tradicionais, inclusive do meio rural ao qual estáo conectados originalmente alguns deles (da Finlândia e Holanda). Seu êxito eleitoral passa por sua transformação em partidos catch all populistas, como a FN francesa (SUREL, 2019).

Comprova-se que somente alguns partidos têm perfil de partidos-nicho, ou seja, centrados em uma issue principal, sobretudo na sua criação, mas não é uma proposta generalizada na maioria. O exemplo mais perfeito é o UKIP britânico como partido anti-UE, que repudia a política migratória europeia (EVANS e MELLON, 2019). Nesse grupo está a Liga Norte italiana, que tem defendido a independência da Padania ou zone norte da Itália, e o Bloco Flamengo holandês, que defende a independência de Flandres. Os Partidos do Progresso dinamarquês e norueguês foram criados como partidos anti-impostos, e o partido grego ANEL como contrário às medidas de austeridade promovidas pela União Europeia com a crise econômica de 2008 (MYLONAS, 2016). A União Democrática de Centro, na Suíça, teve origem na defesa do setor dos comerciantes. Em geral, os partidos-nicho de extrema direita são pequenos, estão mal organizados e tendem a desaparecer. Sua permanência só é possível quando desenvolvem um programa mais amplo no campo da escolha social e buscam apoio eleitoral através da moderação.

\section{Os partidos de extrema direita e a governabilidade}

A última variável deste estudo é o efeito que os partidos de extrema direita têm sobre a governabilidade dos países. Paralelamente deve-se considerar a possibilidade de que os partidos de extrema direita acabem, ou náo, conformando um bloco com os mais próximos no espaço ideológico. 
Começando pela formação de coalizóes de governo, nos dados observa-se que, na metade dos casos, os partidos de extrema direita participaram de coalizóes de governo (Quadro 3). Concretamente, isso ocorreu de maneira estável na Áustria, Noruega, Suíça, Itália e Grécia, enquanto na Finlândia e Holanda formaram coalizóes apenas de maneira limitada, em alguma ocasiáo específica, e na Dinamarca o partido de extrema direita frequentemente tem dado apoio parlamentar aos governos minoritários. Por isso pode-se dizer que, nesses países, prima-se por uma cultura consensual com tendências centristas, e os sistemas de partidos desenvolveram um caráter homogêneo, com um multipartidarismo moderado que integra os partidos de extrema direita, os quais obtêm um importante apoio eleitoral. Pelo contrário, na Suécia e na Alemanha é explícita a existência de dificuldades de alcançar o consenso com esses partidos, aos quais se aplica o "cordão sanitário", rejeitando-os nas coalizóes, especialmente pela democracia cristá, por serem considerados antissistema. Isso também ocorre na Dinamarca, Noruega e Holanda. O mesmo acontece na França, onde a Frente Nacional se considera um partido antissistema (KNAPP, 2002), e os partidos de centro-esquerda e centro-direita se coligaram para competir contra ele no segundo turno das eleiçóes presidenciais de 2002 e 2017.

Em geral, os partidos de extrema direita não geraram crises de governabilidade em seus países, salvo na Bélgica, onde sua existência dificultou muito a formação do governo. De fato, esse é o país europeu que tem o sistema mais complexo de formação de coalizóes de governo (DE WINTER, TIMMERMANS e DUMONT, 2000). O mesmo também ocorre de forma ocasional na Itália, onde a LN dificultou as negociaçóes para a formaçấo de governo, mas nunca impediu que o partido socialdemocrata, que tem a posição central do sistema, formasse governos minoritários (BERGMAN, 2000). Os efeitos sobre a governabilidade não se podem avaliar no caso da França devido à pobre representação parlamentar da FN. Tampouco é viável no Reino Unido por sua limitada representatividade, nem na Espanha pelo curto período de tempo da existência do Vox.

Quadro 1 - Resumo das características do voto de extrema direita na Europa (1999-2019)

\begin{tabular}{|l|c|c|c|c|c|}
\hline & $\begin{array}{c}\text { Tendência } \\
\text { de voto }\end{array}$ & $\begin{array}{c}\text { Produz } \\
\text { fragmentaçáo }\end{array}$ & $\begin{array}{c}\text { Realinhamento } \\
\text { do eleitorado }\end{array}$ & $\begin{array}{c}\text { Tendência de } \\
\text { Polarizaçáo }\end{array}$ & $\begin{array}{c}\text { Forma } \\
\text { coalizóes }\end{array}$ \\
\hline Alemanha & Ascendente & SIM & NÃO & Descendente & NÃO \\
\hline Áustria & $\begin{array}{l}\text { Levemente } \\
\text { ascendente }\end{array}$ & SIM & $\begin{array}{c}\text { SIM } \\
\text { Secular }\end{array}$ & Ascendente & SIM \\
\hline Bélgica & Descendente & NÃO & NÃO & Descendente & NÃO \\
\hline
\end{tabular}




\begin{tabular}{|c|c|c|c|c|c|}
\hline Dinamarca & $\begin{array}{l}\text { Levemente } \\
\text { ascendente }\end{array}$ & NÃO & $\begin{array}{c}\text { SIM } \\
\text { Secular }\end{array}$ & $\begin{array}{l}\text { Levemente } \\
\text { ascendente }\end{array}$ & NÃO \\
\hline Espanha & Ascendente & SIM & NÁO & Ascendente & s/d \\
\hline Finlândia & $\begin{array}{l}\text { Fortemente } \\
\text { ascendente }\end{array}$ & SIM & $\begin{array}{c}\text { SIM } \\
\text { Crítico }\end{array}$ & $\begin{array}{l}\text { Levemente } \\
\text { ascendente }\end{array}$ & SIM \\
\hline França & Estável & SIM & $\begin{array}{c}\text { SIM } \\
\text { Secular } \\
\end{array}$ & Descendente & NÃO \\
\hline Grécia & Estável & SIM & NÁO & Ascendente & SIM \\
\hline Holanda & $\begin{array}{l}\text { Levemente } \\
\text { ascendente }\end{array}$ & SIM & $\begin{array}{c}\text { SIM } \\
\text { Crítico }\end{array}$ & $\begin{array}{l}\text { Levemente } \\
\text { ascendente }\end{array}$ & NÃO \\
\hline Itália & $\begin{array}{l}\text { Fortemente } \\
\text { Ascendente }\end{array}$ & SIM & $\begin{array}{c}\text { SIM } \\
\text { Secular/crítico }\end{array}$ & Descendente & SIM \\
\hline Noruega & $\begin{array}{c}\text { Levemente } \\
\text { Descendente }\end{array}$ & SIM & $\begin{array}{c}\text { SIM } \\
\text { Secular }\end{array}$ & Descendente & SIM \\
\hline $\begin{array}{l}\text { Reino } \\
\text { Unido }\end{array}$ & Estável & SIM & NÃO & Descendente & NÃO \\
\hline Suécia & $\begin{array}{l}\text { Fortemente } \\
\text { ascendente }\end{array}$ & SIM & $\begin{array}{c}\text { Incipiente } \\
\text { Crítico }\end{array}$ & Descendente & NÃO \\
\hline Suíça & $\begin{array}{l}\text { Levemente } \\
\text { ascendente }\end{array}$ & NÃO & $\begin{array}{c}\text { SIM } \\
\text { Secular }\end{array}$ & Descendente & SIM \\
\hline
\end{tabular}

Fonte: Elaboração própria.

\section{Conclusões}

Desta análise cabe concluir, em termos gerais, que houve um processo expansivo da extrema direita ou direita radical em várias fases e que começa no pósguerra, embora tenha alcançado mais importância no século XXI pelo número de países europeus com partido dessa tendência em seus parlamentos. Paralelamente produziuse uma moderação programática dos partidos a medida em que se institucionalizaram.

Constata-se um crescente apoio a esses partidos e, em consequência, um aumento da fragmentação dos sistemas de partidos e um aprofundamento do multipartidarismo, assim como da competição partidária em torno do eixo esquerda/direita. Isso produziu um realinhamento do eleitorado na maior parte dos países, em particular no bloco de centro-direita; trata-se principalmente de um realinhamento secular, com alguns casos de realinhamento crítico.

Os partidos de extrema direita passaram por diversas etapas em relação à polarização dos sistemas de partidos. Radicalizaram seus programas na primeira década do século XXI, mas se moderaram na segunda década com o objetivo de alcançar os eleitores de centro-direita e se institucionalizar. Muitos deles são partidos-nicho na sua 
origem e, embora partindo da vantagem inicial que é a novidade que representam ante um eleitorado decepcionado com a política dos partidos tradicionais, nascem pequenos e mal organizados por serem muito dependentes de um único líder. Esta é a razão pela qual se transformaram para ampliar o apoio eleitoral.

Seus programas articulam os conteúdos de escolha social, principalmente em torno das propostas conservadoras tradicionais, e não dão importância alta às propostas neoliberais em torno da defesa do mercado. Ao contrário, sua moderação programática deve-se à adoção de posiçôes favoráveis à intervenção do Estado. A causa dessa mudança é estratégica, já que os partidos tentam buscar o maior apoio eleitoral, e o centro se identifica com o consenso existente na Europa em defesa das políticas sociais do Welfare State. Também se destaca sua defesa do nacionalismo. Ambas as questóes refletem uma orientação discriminatória a respeito dos imigrantes.

$\mathrm{Na}$ perspectiva da governabilidade, existem dois modelos de partidos de extrema direita na Europa. Um é o dos partidos integrados no sistema e que, por isso, formam regularmente coalizóes de governo ou legislativas. Outro grupo pequeno é formado pelos que sempre são excluídos das negociaçóes e em torno dos quais se forma um cordão sanitário por parte dos demais partidos do sistema, por serem repudiados pela maioria dos eleitores. Estes são rejeitados particularmente pela democracia cristã. Estes partidos chegaram a ser configurados como partidos antissistema, como na França.

Náo há uma pauta completamente homogênea na evolução e situação dos partidos de extrema direita na Europa. Assim, alguns países têm esses partidos desde meados do século passado, e em outros esse é um fenômeno muito recente, como na Espanha. A fragmentação tem efeitos diferentes em cada sistema de partidos. Pode-se distinguir entre os países nos quais a extrema direita produz um mero aumento de partidos pequenos ou médios, que são particularmente os nórdicos, mais Bélgica, Holanda e Suíça, e aqueles em que a extrema direita produz a desconcentração do voto, como na Áustria, Alemanha, Espanha, Grécia e Itália.

Os efeitos negativos dos partidos de extrema direita sobre a estabilidade democrática dependem de que seu apoio eleitoral seja suficientemente elevado no contexto do sistema. Assim, nos casos de Bélgica, Alemanha e Grécia está ocorrendo uma tendência de alta nos indicadores de fragmentação e de polarização, podendo se produzir dificuldades para a governabilidade se estes crescerem muito. Espanha se aproxima dessa situação, já que a polarização de Vox é extrema (9,4 de 10) segundo a percepção do eleitorado (CIS, 2020), pois seu programa ainda não foi analisado no 
Manifesto Project. Também na Holanda ocorre uma fragmentação e uma polarização em aumento, mas esta é moderada. Como consequência disso, esses partidos dificultam enormemente a formação de governos na Bélgica e Espanha e levam à formação de grandes coalizóes na Alemanha, pois não é possível uma exclusivamente de direita.

Manuel Sánchez de Dios é Professor da Universidad Complutense de Madrid. E-mail: MANUESAN@ucm.es.

\section{Referências}

ANDERSEN, Jørgen G.; BJØRKLUND, Tor. Structural changes and new cleavages: The Progress Parties in Denmark and Norway. Acta Sociologica, v. 33, n. 3, p. 195-217, 1990. Disponível em: <https://www.jstor.org/stable/4200798>. Acesso em: 09 ago. 2021.

ANTÓN, Joan; RUIZ, Encarna. Fascismo: la utopía fascista. In: ANTÓN, Joan (Coord.). Ideologías y movimientos políticos contemporáneos. Madrid: Tecnos, 1998. p. 131-166.

BERGMAN, Torbjörn. Sweden: When Minority Cabinets Are the Rule and Majority Coalitions the Exception. In: MULLER, Wolfgang; STRØM, Kaare (Eds.). Coalition Governments in Western Europe. Oxford University Press, 2000. p. 192-230.

BEYENS, Stefanie; LUCARDIE, Paul; DESCHOUWER, Kris. The Life and Death of New Political Parties in the Low Countries. West European Politics, v. 39, n. 2, p. 257-277, 2016. doi: 10.1080/01402382.2015.1066589

BISCHOF, Daniel. Towards a renewal of the niche party concept: Parties, market shares and condensed offers. Party Politics, v. 23, n. 39, p. 220-235, 2017. doi: /10.1177/1354068815588259

CARRERAS, Miguel; MORGERNSTERN, Scott; SU, Yen-Pin. Refining the theory of partisan alignments: Evidence from Latin America. Party Politics, v. 21, n. 5, p. 671-685, 2015. doi: $10.1177 / 1354068813491538$

CENTRO DE INVESTIGACIONES SOCIOLÓGICAS (CIS). Barómetro $n^{\circ} 3271$, de enero de 2020. Madrid: Ministerio de la Presidencia, 2020.

COLOMER, Josep M. Son los partidos los que eligen los sistemas electorales (o las leyes de Duverger cabeza abajo). Revista Española de Ciencia Política, n. 9, p. 39-63, 2003. Disponível em: <https://recyt.fecyt.es/index.php/recp/article/view/37346>.

DAMGAARD, Erik. The Life and Death of Government Coalitions. In: MULLER, Wolfgang; STRØM, Kaare (Eds.). Coalition Governments in Western Europe. Oxford University Press, 2000. p. 231-263. 
DE WINTER, Lieven; TIMMERMANS, Arco; DUMONT, Patrick. Belgium: On Government Agreements, Evangelists, Followers, and Heretics. In: MULLER, Wolfgang; STRØM, Kaare (Eds.). Coalition Governments in Western Europe. Oxford University Press, 2000. p. 300-355.

DESCHOUVER, Kris. The Colour Purple: The End of Predictable Politics in the Low Countries. In: WEBB, Paul; FARRELL, David; HOLLIDAY, Ian (Eds.). Political Parties in Advanced Industrial Democracies. Oxford University Press, 2002. p. 151-180.

DOWNS, Anthony. An Economic Theory of Democracy. New York: Harper and Row, 1957.

DUVERGER, Maurice. Los partidos políticos. México: Fondo de Cultura Económica, 1981.

ENNSER-JEDENASTIK, Laurenz. Welfare Chauvinism in Populist Radical Right Platforms: The Role of Redistributive Justice Principles. Social Policy and Administration, v. 52, n. 1, p. 293-314, 2018. doi: $10.1111 /$ spol.12325

ERZEEL, Silvia; RASHKOVA, Ekaterina. Still men's parties? Gender and the radical right in comparative perspective. West European Politics, v. 40, n. 4, p. 812-820, 2017. doi: 10.1080/01402382.2017.1286181

EVANS, Geoffrey; MELLON, Jonathan. Immigration, Euroscepticism, and the rise and fall of UKIP. Party Politics, v. 24, n. 1, p. 76-87, 2019. doi: 10.1177/1354068818816969

FERRER, Covadonga. El sistema político de Suiza. In: SÁNCHEZ MEDERO, Gema; SÁNCHEZ MEDERO, Rubén (Dirs.). Sistemas políticos en Europa. Valencia: Tirant Lo Blanch, 2014. p. 443470.

FERRERA, Maurizio. Ideology, Parties and Social Politics in Europe. West European Politics, v. 37, n. 2, p. 420-438, 2014. doi: 10.1080/01402382.2014.887872

GALLAHER, Michael; LAVER, Michael; MAIR, Peter. Representative Government in Modern Europe. McGraw Hill, 1992.

GOLDBERG, Andreas C. The evolution of cleavage voting in four Western countries: Structural, behavioral or political dealignment? European Journal of Political Research, v. 59, n. 1, p. 68-90, 2020. doi: 10.1111/1475-6765.12336

GREEN-PEDERSEN, Christopher; OTJES, Simon. A hot topic? Immigration on the agenda in Western Europe. Party Politics, v. 25, n. 3, p. 424-434, 2019. doi: 10.1177/1354068817728211

GRIFFIN, Roger. Fascismo. Madrid: Alianza Editorial, 2019.

HERNÁNDEZ, Adolfo; LAIZ, Consuelo. Atlas de elecciones y partidos políticos en España (19772016). Madrid: Síntesis, 2017.

JANKOWSKI, Michael; SCHNEIDER, Sebastian; TEPE, Markus. Ideological alternative? Analyzing Alternative fur Deutschland candidates' ideal points via black box scaling. Party Politics, v. 23, n. 6, p. 704-716, 2017. doi: 10.1177/1354068815625230

KITSCHELT, Herbert; MCGANN, Anthony. The Radical Right in Western Europe. A Comparative Analysis. Michigan: The University of Michigan Press, 1995.

KNAPP, Andrew. France: Never a Golden Age. In: WEBB, Paul; FARRELL, David; HOLLIDAY, Ian (Eds.). Political Parties in Advanced Industrial Democracies. Oxford University Press, 2002. p. 107150 .

LAAKSO, Markku; TAAGAPERA, Rein. Effective number of parties: A measure with application to West Europe. Comparative Political Studies, v. 12, n. 1, p. 3-27, 1979. doi: $10.1177 / 001041407901200101$ 
LAUVAUX, Philippe. Les grandes démocraties contemporaines. Paris: PUF, 1990.

LUCARDIE, Paul. The Netherlands. European Journal of Political Research, v. 42, n. 7-8, p. 10291036, 2003. doi: 10.1111/j.0304-4130.2003.00131.x

MAIR, Peter. Party System Change. In: KATZ, Richard; CROTTY, William (Eds.). Handbook of Party Politics. Londres: Sage, 2011. p. 63-74.

MACRIDIS, Roy C. Contemporary Political Ideologies. New York: Harper Collins, 1992.

MAGUID, Bonnie. Competition between Unequals: The Role of Mainstream Party Strategy in Niche Party Success. The American Political Science Review, v. 99, n. 3, p. 347-359, 2005. doi: $10.1017 /$ S0003055405051701

MANIFESTO PROJECT. [Database]. Disponível em: <https://manifesto-project.wzb.eu/>. Acesso em: 31 jul. 2021.

MELLA, Manuel. Los sistemas de partidos. In: MARTÍNEZ, Miguel; MELLA, Manuel (Eds.). Partidos políticos y sistemas de partidos. Madrid: Trotta, 2012. p. 181-206.

MILAZZO, Caitlin; MOSER, Robert; SCHNEIDER, Ethan. Social Diversity Affects the Number of Parties Even Under First-Past the-Post Rules. Comparative Political Studies, v. 51, n. 7, p. 938-974, 2018. doi: 10.1177/0010414017720704

MOSCA, Lorenzo; TRONCONI, Filippo. Beyond left and right: the eclectic populism of the Five Star Movement. West European Politics, v. 42, n. 6, p. 1258-1283, 2019. doi: 10.1080/01402382.2019.1596691

MUDDE, Cas. Populist Radical Right Parties in Europe. Cambridge: Cambridge University Press, 2007.

MULLER, Wolfgang. Austria: Tight Coalitions and Stable Gobvernment. In: MULLER, Wolfgang; STRØM, Kaare (Eds.). Coalition Governments in Western Europe. Oxford University Press, 2000. p. 86-125.

MYLONAS, Harris. Greece. European Journal of Political Research Political Data Yearbook, v. 55, n. 1, p. 113-123, 2016. doi: 10.1111/2047-8852.12124.

NARUD, Hanne M.; STRØM, Kaare. Norway: A Fragile Coalitional Order. In: MULLER, Wolfgang; STRØM, Kaare (Eds.). Coalition Governments in Western Europe. Oxford University Press, 2000. p. 158-191.

NOUSIAINEN, Jaakko. Finland: The Consolidation of Parliamentary Governance. In: MULLER, Wolfgang; STRØM, Kaare (Eds.). Coalition Governments in Western Europe. Oxford University Press, 2000. p. 264-299.

ROVNY, Jan; POLK, Jonathan. New wine in old bottles: Explaining the dimensional structure of European party systems. Party Politics, v. 25, n. 1, p. 12-24, 2019. doi: 10.1177/1354068817752518 SAALFELD, Thomas. Germany: Stable Parties, Chancellor Democracy, and the Art of Informal Settlement. In: MULLER, Wolfgang; STRØM, Kaare (Eds.). Coalition Governments in Western Europe. Oxford University Press, 2000. p. 32-85.

SARTORI, Giovanni. Ingeniería constitucional comparada. Madrid: Alianza, 2003.

SARTORI, Giovanni. Partidos y sistemas de partidos. Madrid: Alianza, 1980.

SCARROW, Susan E. Party Decline in the Parties State? The Changing environment of German Politics. In: WEBB, Paul; FARRELL, David; HOLLIDAY, Ian (Eds.). Political Parties in Advanced Industrial Democracies. Oxford University Press, 2002. p. 77-106. 
SIKK, Allan. Newness as a Winning Formula for New Political Parties. Party Politics, v. 18, n. 4, p. 465-486, 2011. doi: 10.1177/1354068810389631

SCHUMACHER, Gijs; VAN KERSBERGEN, Kees. Do mainstream parties adapt to the welfare chauvinism of populist parties? Party Politics, v. 22, n. 3, p. 300-312, 2016. doi: $10.1177 / 1354068814549345$

SUNDBERG, Jan. The Scandinavian Party Model at the Crossroads. In: WEBB, Paul; FARRELL, David; HOLlidAY, Ian (Eds.). Political Parties in Advanced Industrial Democracies. Oxford University Press, 2002. p. 181-216.

SUREL, Yves. How to stay populist? The Front National and the changing French party system. West European Politics, v. 42, n. 6, p. 1230-1257, 2019. doi:10.1080/01402382.2019.1596693

THIÉBAULT, Jean-Louis. France: Forming and Maintaining Government Coalitions in the Fifth Republic. In: MULLER, Wolfgang; STRØM, Kaare (Eds.). Coalition Governments in Western Europe. Oxford University Press, 2000. p. 498-128.

TIMMERMANS, Arco; ANDEWEG, Rudy. The Netherlands: Still the Politics of Accomodation? In: MULLER, Wolfgang; STRØM, Kaare (Eds.). Coalition Governments in Western Europe. Oxford University Press, 2000. p. 356-398.

VERZICHELLI, Luca; COTTA, Maurizio. Italy: From 'Constrained' Coalitions to Alternating Governments? In: MULLER, Wolfgang; STRØM, Kaare (Eds.). Coalition Governments in Western Europe. Oxford University Press, 2000. p. 433-497.

WANG, Ching-Hsing. The effects of Party Fractionalization and Party Polarization on Democracy. Party Politics, v. 20, n. 5, p. 687-699, 2014. doi: 10.1177/1354068812448691

WEBB, Paul. Political Parties in Britain: Secular Decline or Adaptive Resilience? In: WEBB, Paul; FARRELL, David; HOLlIDAY, Ian (Eds.). Political Parties in Advanced Industrial Democracies. Oxford University Press, 2002a. p. 16-45.

WEBB, Paul. Conclusion: Political Parties and Democratic Control in Advanced Industrial Societies. In: WEBB, Paul; FARRELL, David; HOLLIDAY, Ian (Eds.). Political Parties in Advanced Industrial Democracies. Oxford University Press, 2002b. p. 438-460.

WESTLAKE, Daniel. Multiculturalism, political parties, and the conflicting pressures of ethnic minorities and far-right parties. Party Politics, v. 24, n. 4, p. 421-433, 2018. doi: $10.1177 / 1354068816678881$

WUTTKE, Alexander. New political parties through the voters' eyes. West European Politics, v. 43, n. 1, p. 22-48, 2020. doi: 10.1080/01402382.2019.1603940

Texto recebido em 15 de janeiro de 2021. Aprovado em 03 de fevereiro de 2021. 